\title{
UMA PROPOSTA DE MENSURAÇÃO DA ECOEFICIÊNCIA A PARTIR DAS COMPETÊNCIAS ORGANIZACIONAIS E DO AGIR ORGANIZACIONAL
}

\author{
Flávio Augusto Cella-de-Oliveira \\ Doutorando em Administração pela Universidade Federal do Paraná - UFPR \\ flaviocella@yahoo.com.br \\ Luciano Munck \\ Professor e pesquisador na Universidade Estadual de Londrina - PPGA/UEL \\ Pós-Doutor pela Ivey Business School da Western University - Canada \\ munck@uel.br
}

\begin{abstract}
RESUMO
No estudo da sustentabilidade organizacional (SO) destaca-se o Triple Bottom Line (TBL), composto pelos pilares econômico, ambiental e social. A ecoeficiência é um conceito que agrega os pilares econômico e ambiental. A teoria do agir organizacional compreende os fenômenos organizacionais como processos que permitem que a SO seja compreendida como um agir organizacional e também seja visualizada como uma competência organizacional. Mediante esta discussão, o objetivo dessa pesquisa foi estruturar um caminho para avaliação da ecoeficiência por meio de indicadores pautados na lógica das competências. Tal construto foi ilustrado tendo como base um estudo de caso de uma indústria de acumuladores de energia - baterias automotivas.
\end{abstract}

Palavras-chave: Agir organizacional; Competências organizacionais; Ecoeficiência; Indicadores; Sustentabilidade organizacional, Triple Bottom Line.

\section{A PROPOSAL FOR ECO-EFFICIENCY MEASUREMENT, THROUGH ORGANIZATIONAL COMPETENCES AND ORGANIZATIONAL ATTITUDE}

\begin{abstract}
The Triple Bottom Line - TBL, emerges when discussing organizational sustainability in relation to economic, environmental and social pillars. In Organizational Sustainability - OS, the TBL pillars are understood as three small sustaining entities. Emerging from this point is eco-efficiency, which represents economical and environmental pillars. The Organization Attitude Theory expresses a point of view to see the organizational phenomenons, such as processes that can be understood in the SO as organizational competences. The research was built with the intent to measure ecoefficiency according to indicators based on organizational competences. This situation was illustrated with a case study in an energy accumulators industry - cars batteries.
\end{abstract}

Key words: Eco-efficiency; Indicators; Organizational action; Organizational skills; Organizational susteinability; Triple Bottom Line. 


\section{INTRODUÇÃO}

A sustentabilidade é um debate presente em muitos segmentos da sociedade e também nas organizações, sob a denominação de sustentabilidade organizacional - SO. Neste contexto, resgatase o Triple Bottom Line - TBL (Elkington, 1999), que visa balancear o desenvolvimento de seus três pilares: econômico, ambiental e social. Têm-se acompanhado o alinhamento de um significativo número de organizações buscando desenvolver-se de acordo com o TBL e, como mostram vários autores (Dillick \& Hockerts, 2002; Jamali, 2006; Lins \& Zylbersztajn, 2010; Young \& Tilley, 2006), a academia também tem empregado seus esforços no estudo da sustentabilidade organizacional.

Na sustentabilidade organizacional os pilares do Triple Bottom Line são compreendidos por vários autores (Dillick \& Hockerts, 2002; Jamali, 2006; Kranjc \& Glavic, 2005) como sustentabilidades menores (SO econômica, SO ambiental e $\mathrm{SO}$ social) que compõem a sustentabilidade organizacional. A partir de então, Dias et al. (2011) criaram uma framework para sustentabilidade organizacional, que também apresenta o entendimento dos três pilares do TBL como três sustentabilidades que, quando relacionadas duas a duas, resultam em três fenômenos de relacionamento, que são: ecoeficiência (representante da integração das sustentabilidades econômica e ambiental); inserção socioeconômica (representante da integração das sustentabilidades econômica e social); e justiça socioambiental (representante da integração das sustentabilidades ambiental e social). Assim, apontam os autores que, ao trabalhar concomitantemente estes fenômenos, estarão sendo desenvolvidas as três sustentabilidades e, por conseguinte, a sustentabilidade organizacional.

Para compreensão da framework, resgata-se a Teoria do Agir Organizacional - TAO (Maggi, 2006) que, por sua vez, exprime uma maneira de ver e conceber os fenômenos organizacionais em termos de processos. Sob este prisma, conforme apresentado por Munck, Munck e Souza (2011), a sustentabilidade organizacional pode ser vista como um agir organizacional e, por sua vez, seus elementos entendidos como subagires.

Ainda para os autores, o agir também está por trás das competências organizacionais que, de acordo com Turner e Crawford (1994), assim como Hamel (1994), são conjuntos de conhecimentos, habilidades e tecnologias necessárias para que a organização desenvolva atribuições e responsabilidades. Assim, pode-se inferir que o grau de desenvolvimento destas competências determina a capacidade da organização atingir os resultados almejados e, portanto, a capacidade de desenvolver a competência sustentabilidade organizacional.

Devido à complexidade da sustentabilidade organizacional, este trabalho se atém, por motivos didáticos, ao fenômeno ecoeficiência, que integra a caminhada rumo à sustentabilidade organizacional, contudo, para tal, é preciso uma reestruturação dos processos produtivos, e para isto utilizar-se a lógica das competências organizacionais. Neste processo de mudanças demandam-se ferramentas que permitam conhecer o grau de desenvolvimento da competência. Visando preencher esta lacuna, busca-se, por meio deste trabalho, os indicadores de ecoeficiência, os quais são interpretados, nesta pesquisa, como entregas de uma competência e permitem uma avaliação do quão desenvolvida está a competência em análise.

A partir de então, este trabalho tem como objetivo a estruturação de um caminho para avaliação da ecoeficiência. Em relação aos processos metodológicos adotados, a pesquisa realizada teve caráter, tanto qualitativo quanto quantitativo. Em um primeiro momento, foi realizada uma revisão bibliográfica para posterior elaboração de um instrumento de mensuração da competência ecoeficiência por meio de indicadores de entregas esperadas, em seguida foi realizado um estudo de caso em uma indústria de acumuladores de energia onde tal instrumento foi aplicado.

\section{FUNDAMENTAÇÃO TEÓRICA}

Esta fundamentação teórica trata de assuntos chave, tais como sustentabilidade e o Triple Bottom Line, para que então sejam compreendidos o modelo de sustentabilidade utilizado e o 
fenômeno ecoeficiência. Ainda, a teoria do agir organizacional e a lógica das competências foram abordadas a fim de conferir suporte aos indicadores de ecoeficiência apresentados ao final desta seção.

\subsection{Sustentabilidade organizacional}

Aproximando o debate da sustentabilidade do contexto organizacional, têm-se a sustentabilidade organizacional como indutora de um novo modelo de gestão de negócios que leva em conta, além da dimensão econômica, as dimensões ambiental e social. Assim, esta agenda inicia-se em empresas que entendem que suas atividades impactam o ambiente no qual estão inseridas - seja o meio ambiente, seja o meio social (Lins \& Zylbersztajn, 2010).

Neste contexto, emerge o Triple Bottom Line, uma expressão cunhada por Elkington (1999), para quem o modelo de negócios tradicional, que só considerava fatores econômicos na avaliação de uma empresa, expande-se para um novo modelo ao contemplar a performance ambiental e social da companhia, além da financeira. Assim, para Lemme (2010), o conceito do Triple Bottom Line ressalta que a sustentação dos resultados das empresas no longo prazo depende da conservação e do desenvolvimento das diversas formas de capital, incluindo o ambiental e social.

Em termos simples, o Triple Bottom Line está centrado não apenas no valor econômico das organizações, mas também no valor ambiental e social, ou seja, propõe uma estrutura em pilares (econômico, ambiental e social) onde cada um é vital para atingir a sustentabilidade. Elkington (1999) aponta que, na medida em que se caminha para o terceiro milênio, está-se embarcando em uma revolução cultural global conduzida pelas organizações.

Embora o Triple Bottom Line seja um modelo de hierarquização que apresenta pilares direcionadores para o trato da sustentabilidade organizacional, o estudo da sustentabilidade organizacional carece de instrumentos e ferramentas de gestão que permitam sua operacionalização, por isso recorre-se a framework de sustentabilidade organizacional de Dias et al. (2011), a qual foi concebida exclusivamente para trabalhar a sustentabilidade organizacional e, por isso, será vista na próxima seção.

\subsection{Modelo de sustentabilidade organizacional}

A partir dos construtos de vários autores (Savitz \& Weber, 2006; Elkington, 1999; Souza, 2010; Munck, Munck \& Souza, 2011; Dias et al., 2011), visando a integração dos três pilares das sustentabilidades (SO econômica, SO ambiental e SO social), as quais, se adequadamente desenvolvidas, são capazes de proporcionar um satisfatório estado de sustentabilidade organizacional. O embasamento desta construção pode ser encontrado ainda em diversos outros autores (Dillick \& Hockerts, 2002; Jamali, 2006; Kranjc \& Glavic, 2005; Callado, 2010), o que confere sustentação ao apresentado. A partir de tais autores, o trabalho de Dias et al. (2011) propõem uma estrutura conceitual (framework) capaz de representar a integração propiciadora de uma melhor compreensão da sustentabilidade organizacional, que é apresentada na Figura 1.

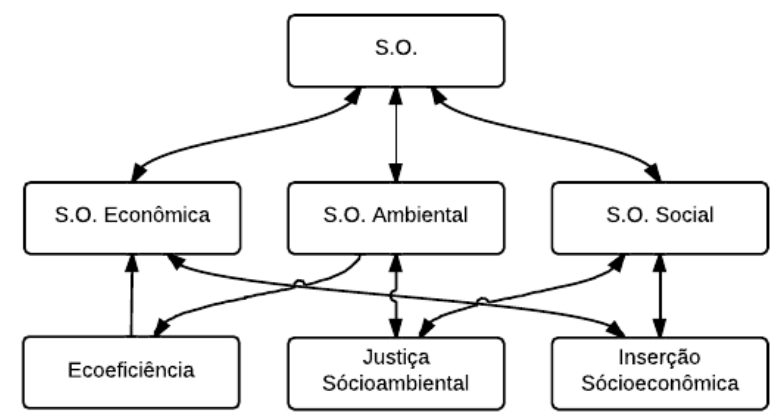

Figura 1. Framework de sustentabilidade organizacional Fonte: Dias et al. (2011) 
Como resultado da interação das sustentabilidades organizacionais econômica, ambiental e social, duas a duas, surgem os fenômenos de relacionamento, que são: ecoeficiência, inserção socioeconômica, e justiça socioambiental. Tal construto também é abordado por Elkington (1999) e Savitz e Weber (2006) e tem seus elementos definidos na figura 2.

\begin{tabular}{|l|l|}
\hline \multicolumn{1}{|c|}{ CONCEITO } & \multicolumn{1}{|c|}{ DESCRIÇÃO } \\
\hline $\begin{array}{l}\text { Sustentabilidade } \\
\text { organizacional }\end{array}$ & $\begin{array}{l}\text { Representação sistêmica do equilíbrio entre as sustentabilidades econômica, ambiental e social. } \\
\text { Neste contexto, entende-se por equilíbrio o balanceamento de investimentos e resultados nas três } \\
\text { sustentabilidades (econômica, ambiental e social) de acordo com os objetivos organizacionais. Por } \\
\text { representação sistêmica, entende-se a conjunção das três sustentabilidades, resultando, assim, na } \\
\text { sustentabilidade organizacional. }\end{array}$ \\
\hline $\begin{array}{l}\text { Sustentabilidade } \\
\text { organizacional } \\
\text { econômica }\end{array}$ & $\begin{array}{l}\text { Subsistema da sustentabilidade organizacional que representa a realização da ecoeficiência e da } \\
\text { inserção socioeconômica. Entende-se por realização o alcance dos indicadores definidos para } \\
\text { medição da ecoeficiência e da inserção socioeconômica. }\end{array}$ \\
\hline $\begin{array}{l}\text { Sustentabilidade } \\
\text { organizacional } \\
\text { ambiental }\end{array}$ & $\begin{array}{l}\text { Subsistema da sustentabilidade organizacional que representa a realização da justiça } \\
\text { socioambiental e ecoeficiência. Entende-se por realização o alcance dos indicadores definidos } \\
\text { para medição da justiça socioambiental e ecoeficiência. }\end{array}$ \\
\hline $\begin{array}{l}\text { Sustentabilidade } \\
\text { organizacional } \\
\text { social }\end{array}$ & $\begin{array}{l}\text { Subsistema da sustentabilidade organizacional que representa a realização da justiça } \\
\text { socioambiental e inserção socioeconômica. Entende-se por realização o alcance dos indicadores } \\
\text { definidos para medição da justiça socioambiental e inserção socioeconômica. }\end{array}$ \\
\hline Ecoeficiência & $\begin{array}{l}\text { Componente da sustentabilidade organizacional que combina o desenvolvimento ambiental com o } \\
\text { desenvolvimento econômico, ao mesmo tempo em que reduz os impactos ambientais e promove a } \\
\text { utilização racional dos recursos naturais. }\end{array}$ \\
\hline $\begin{array}{l}\text { Inserção } \\
\text { socioeconômica } \\
\text { garante aos indivíduos recursos suficientes para o seu acesso a oportunidades e desenvolvimento } \\
\text { equitativo em relação aos objetivos organizacionais. }\end{array}$ \\
\hline $\begin{array}{l}\text { Justiça } \\
\text { socioambiental }\end{array}$ & $\begin{array}{l}\text { Componente da sustentabilidade organizacional que assegura aos indivíduos o recebimento } \\
\text { equilibrado e contextual dos malefícios e benefícios sociais e ambientais advindos das atividades } \\
\text { organizacionais. }\end{array}$ \\
\hline
\end{tabular}

Figura 2. Conceitos da framework de sustentabilidade organizacional

Fonte: Dias et al. (2011)

Dias et al. (2011) explicam que os componentes da framework devem estar alinhados, uma vez que os processos ocorrem em razão de sua relação balanceada com os ambientes externo e interno, assim como o Triple Bottom Line. A framework apresenta uma perspectiva sistêmica que delineia a interdependência dos elementos em que o mínimo abalo de um dos elementos é capaz de desbalancear toda a estrutura. Embora graficamente lembre uma estrutura hierárquica ela não o é, por isso permite apresentar seu caráter sistêmico representado pelas setas duplas, nas quais se evidenciam a interdependência e interação dos elementos que ocorrem nos dois sentidos.

Como já afirmado, a sustentabilidade organizacional pode ser conquistada trabalhando seus fenômenos de relacionamento (ecoeficiência, inserção socioeconômica e justiça socioambiental). Sendo a framework uma estrutura complexa e abrangente, optou-se, por meio dessa pesquisa, trabalhar com o fenômeno ecoeficiência, por sua vez colaborador do desenvolvimento das sustentabilidades econômica e ambiental, sendo então, abordado com maior profundidade na seção seguinte.

\subsection{Ecoeficiência}

O conceito de ecoeficiência foi desenvolvido pelo World Business Council For Sustainable Development - WBCSD (2000) e é largamente reconhecido pelo mundo empresarial ao reunir os ingredientes essenciais (progresso econômico e ambiental) para o aumento da prosperidade econômica por meio da utilização mais eficiente dos recursos e de menos emissões nocivas para o ambiente (WBCSD, 2000). Salgado (2007) explica que Schmidheiny e o WBCSD publicaram o livro Changing Course: A Global Business Perspective on Development and the Environment 
(Schmidheiny e WBCSD, 1992), no qual procuraram desenvolver um conceito que, ao unir melhorias ambientais e econômicas, pudesse criar um negócio a partir do desafio da sustentabilidade, surgindo então o conceito de ecoeficiência. Tal publicação contribuiu para a mudança da concepção de que a indústria é parte do problema da degradação ambiental. Nas palavras do WBCSD (2000a), a ecoeficiência

[...] atinge-se através da disponibilização de bens e serviços a preços competitivos, que, por um lado, satisfaçam as necessidades humanas e contribuam para a qualidade de vida e, por outro, reduzam progressivamente o impacto ecológico e a intensidade de utilização de recursos ao longo do ciclo de vida, até atingirem um nível que, pelo menos, seja compatível com a capacidade de renovação estimada para o planeta Terra (WBCSD, 2000a).

Visualizando a ecoeficiência na framework de SO, verificou-se que esta representa o desenvolvimento dos pilares econômico e ambiental do Triple Bottom Line. Assim, Dias et al. (2011) explicam que a ecoeficiência transcende a compreensão da forma comumente encontrada na literatura, ou seja, de uma política empresarial de redução de custos com caráter imediatista, passando a ser composta por duas frentes de desenvolvimento, a econômica e a ambiental. Com base no exposto, conclui-se que a ecoeficiência pode ser abordada como um fenômeno que direciona a organização rumo à sustentabilidade, indo além do controle da poluição, como apontado por Schaffel (2010), podendo equilibrar os múltiplos interesses de forma transparente, tornando-se, assim, uma abordagem "pesada", segundo colocações de Vos (2007).

Uma das formas de trabalhar-se a ecoeficiência para o alcance de seus objetivos, é a sua visualização como uma competência para a construção da sustentabilidade organizacional e, assim, no intuito de avançar nesta interação entre ecoeficiência e competências, é tratado no capítulo seguinte a lógica das competências.

\subsection{A lógica das competências organizacionais}

Competência, em nível organizacional, trata-se de um conjunto de habilidades e tecnologia das organizações que lhes permitem realizar ações. Petinelli-Souza e Machado (2006) apontam que nos anos 1990 ganhou notoriedade a questão estratégica das competências disseminada principalmente por Hamel e Prahalad (1990; 1995), sendo então denominadas de competências essenciais, ou core competences. Segundo Hamel e Prahalad (1990), as core competences são capazes de perceber facilmente as demandas dos clientes, e são difíceis de serem imitadas pelos concorrentes.

Competência, então, é uma habilidade para fazer alguma coisa e pode-se dizer que a organização possui competências se puder superar os concorrentes (Mills et al., 2002). Ainda Mills et al. (2002) explicam que não se pode afirmar que a competência é uma coisa que a organização tem ou deixa de ter, e sim que a organização é detentora em determinado nível.

Prahalad e Hamel (1990) abordam a capacidade de articulação e mobilização de recursos organizacionais como a essência da competência. A organização pode deter os ingredientes da competência, mas se não articulá-los com o intuito de gerar entregas não terão validade. Assim, entende-se por entregas os resultados que a organização apresenta por deter uma competência. Com base no inferido, pode-se então dizer que uma organização competente é aquela que detém a capacidade de assegurar condições de obter resultados e, entregar o seu objeto fim (produto, serviço, etc.), de forma eficiente e eficaz. Desta forma, somente pode-se falar em competência quando há entregas.

Com o intuito de dar suporte ao entendimento da sustentabilidade organizacional e da ecoeficiência como competências, é apresentado, na sequência, a teoria do agir organizacional.

\subsection{Teoria do Agir Organizacional - TAO}

O agir organizacional, de acordo com Maggi (2006), exprime uma forma de ver a organização como processos, os quais são duradouros e nunca terminados. Este agir, embora 
flexível, tem caráter regulatório, sendo denominado de agir estruturante. Em meio a estes processos, o autor discorre que o agir demonstra como os indivíduos buscam atingir seus objetivos, ou seja, os meios utilizados para tal, considerando que o agir ganha sentido.

O agir organizacional entende a organização como processos de ações e decisões, os quais, para Maggi (2006), são pautados na racionalidade dos agentes sociais por meio de seus agires. A razão humana, por exemplo, tem caráter intencional, contudo, sua racionalidade a torna limitada e estas características são obrigatoriamente absorvidas pelo agir, uma vez que este é guiado pela racionalidade.

Ainda, de acordo com Maggi (2006), o agir organizacional é um processo que se autoorganiza por meio da criação de ordem e de regras, as quais são variáveis, formais e informais, explícitas e tácitas, conscientes e não-conscientes, prévias e intrínsecas à ação. Essas regras são construídas no decorrer do desenvolvimento do processo e constituem a estruturação do processo no sentido de ação estrutural ou estruturante. Tais regras são produzidas de maneira heterônima ou autônoma, podendo ocorrer por imposição ou discricionariedade.

Maggi (2006) exemplifica o agir organizacional a partir da descrição da execução da obra Octeto em fá maior D803, de Schubert:

[...] estamos na presença de um trabalho coletivo, qualquer que seja a definição que se dê a essa noção; e na presença de um grupo de trabalho, o conjunto. [...] a ação de cada músico dirige-se à ação dos outros músicos, e a de todos se dirige no mínimo à administração do teatro e ao público presente na sala. [...] o processo de ação de cada sujeito, assim como o processo comum do conjunto, está relacionado a outros processos. [...] a adaptação dos meios aos fins concerne, sem dúvida, aos instrumentos que a composição musical exige, mas também ao nível das capacidades, dos conhecimentos e das competências dos músicos, e ao tempo que dedicaram aos ensaios. [...] os músicos parecem dominar completamente os meios e os fins, mas a incerteza jamais será excluída, não se sabe o que pode acontecer. [...] o que faz a diferença é que cada músico queria tocar essa obra, mas não podia fazê-lo sozinho. [...] sendo a execução da música o objetivo comum, os oito músicos cooperam para atingi-lo. E, para que essa cooperação dê certo, eles se coordenam (MAGGI, 2006, p.8).

Tendo como base o exposto no exemplo, verifica-se que o agir organizacional tem como características centrais (Maggi, 2006):

a. Finalização, que constitui a compreensão da relação entre meios, fins e resultados;

b. Estruturação do processo, que envolve a articulação de processos e o entendimento das ações como racionalmente limitadas e intencionais;

c. Cooperação, influenciadora do poder das ações, que, por consequência, influencia a efetividade das decisões, agindo sobre as estratégias organizacionais e relacionamentos sociais.

A partir da TAO, a seção seguinte avança incrementando a framework de sustentabilidade organizacional previamente apresentada.

\subsection{Ecoeficiência e competências}

No entanto, a mera existência de um modelo hierarquizador que aponte elementos para a sustentabilidade organizacional não é suficiente para gestão deste fenômeno. Embora Elkington (1999), assim como outros autores, aponte como ideal o desenvolvimento balanceado dos elementos da sustentabilidade organizacional, as organizações demandam de ferramentas que orientem este processo.

Assim, Munck, Munck e Souza (2011) apontam que, a partir de Maggi (2006), é possível compreender a sustentabilidade organizacional como um agir, ou seja, um processo de ações e decisões e, por sua vez, cada um de seus elementos são subagires deste processo maior. Os agires podem ser visualizados e operacionalizados a partir da lógica das competências quando então a

Revista de Gestão Social e Ambiental - RGSA, São Paulo, v. 8, n. 1, p. 73-88, jan./abr., 2014. 
sustentabilidade organizacional passa a ser entendida como uma competência central, e os demais elementos como competências chave e de suporte, por sua vez, capazes de alavancar a sustentabilidade organizacional, como mostra a Figura 3.

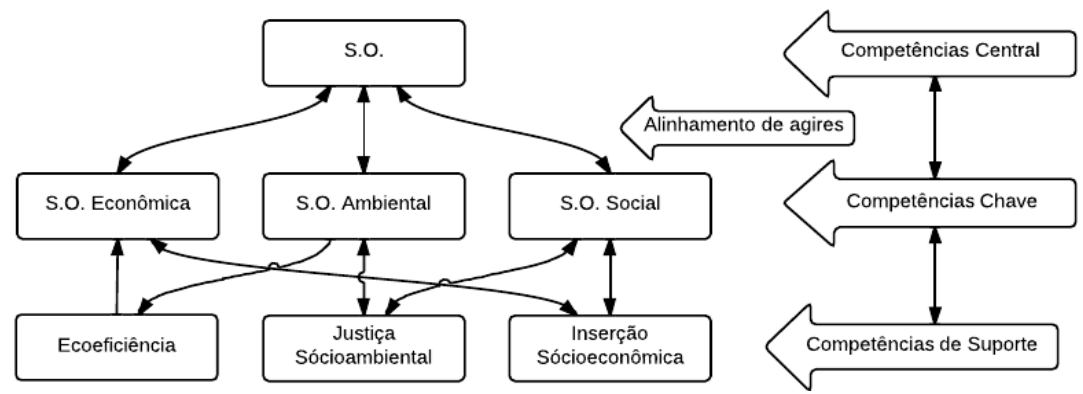

Figura 3. Modelo de Sustentabilidade Organizacional e sua arquitetura de competências.

Fonte: Munck, Munck e Souza (2011)

Como visível na Figura 3, os autores explicam que compreendem a sustentabilidade organizacional como uma competência central, viabilizada pela justaposição das competências chave: SO econômica, SO ambiental e SO social que, por sua vez, são viabilizadas pela interação e pelo atendimento das competências de apoio (ecoeficiência, justiça socioambiental e inserção socioeconômica). Nesse sentido, a sustentabilidade organizacional é vista como um agir organizacional viabilizado pelos subagires, que podem ser operacionalizados pelas competências, como proposto por Munck, Munck e Souza (2011). Ao formular a framework, apresentada na Figura 3, Munck, Munck e Souza (2011) explanam que a competência concede orientações para gestão dos quesitos relacionados à sustentabilidade das organizações, pois permite delimitar e orientar ações objetivas e coerentes com os respectivos agires organizacionais pretendidos.

A partir da framework, afim de alcançar os objetivos deste trabalho, será abordada a competência de suporte ecoeficiência e para tal resgata-se o conceito de entrega, previamente abordado. Para mensuração da competência às entregas são vitais, pois são estas que demonstrarão o quanto a competência é efetiva. Assim, um desafio é levantar quais as entregas representam o atendimento de uma competência e, visando responder este desafio, recorre-se aos indicadores de ecoeficiência para auxiliar neste processo.

Indicadores são parâmetros que fornecem informações sobre o estado de um fenômeno (OECD, 1993). Hanai (2009) explica que os indicadores são capazes de apontar as características de um sistema e clarificar as relações entre as variáveis envolvidas num fenômeno, tornando-o visível. Desta forma, é possível que tanto indicadores quanto entregas sejam considerados processos de ações e decisões de acordo com a TAO, tornando-se possível interpretar um conjunto de indicadores como um conjunto de entregas.

Além desta apresentação sobre indicadores, demanda-se discutir especificamente os indicadores de ecoeficiência para que seja possível dar suporte a conversão destes indicadores em entregas. Desta forma, os indicadores de ecoeficiência são abordados na sequência.

\subsection{Mensuração e indicadores de ecoeficiência por meio de competências}

Tendo compreendido o processo da ecoeficiência e a lógica das competências é possível, por intermédio da TAO, compreender que para atingir a ecoeficiência a organização demanda um conjunto de agires que podem se obtidos pelo desenvolvimento de competências.

WBCSD (2000) apresenta indicadores de ecoeficiência que visam avaliações com o intuito de atingir mais valor para a organização utilizando menos materiais, energia e reduzindo as emissões. O World Business Council For Sustainable Development - WBCSD (2000) detém o pioneirismo da discussão em torno da ecoeficiência, sendo sua metodologia amplamente difundida. Contudo, outra metodologia que trata de indicadores amplamente aceitos na área de sustentabilidade é a editada pelo Global Reporting Initiative - GRI (2006), que, na visão de Savitz e 
Weber (2006), é o principal padrão mundial para sustentabilidade.

GRI (2006) explica que o modelo foi concebido para ser utilizado por organizações de qualquer porte, setor ou localidade, levando em conta as questões práticas aplicáveis na divulgação do desempenho de sustentabilidade da organização. Os indicadores do GRI estão organizados nas categorias econômica, meio ambiental, direitos humanos, práticas trabalhistas, responsabilidade pelo produto, sociedade. Embora o GRI não apresente indicadores de ecoeficiência, diversos autores (Maxime, Marcotte \& Arcand, 2006; Schaltegger \& Wagner, 2005) sugerem realizar uma avaliação baseada nos indicadores econômicos e ambientais.

Os indicadores da WBCSD são dependentes de medições e unidades, o que não se mostra compatível com o trato de competências. Já os indicadores do GRI, por serem originalmente concebidos para elaboração de relatórios, não são formatados precisamente como indicadores, uma vez que solicitam descrições e comentários de fenômenos, ou seja, fornecem um roteiro para criação de relatórios. Assim, um adequado grupo de indicadores deve conter sentenças que indiquem ao usuário uma situação a ser avaliada, conforme sugerido pela OECD (1993) e Hanai (2009).

A partir de então, demandou-se a criação de um grupo de indicadores de ecoeficiência os quais foram adaptados dos instrumentos da WBCSD e GRI, com aporte ainda em outros autores como OECD (1993), Meadows (1998) e Maxime, Marcotte e Arcand (2006). Como resultado desta adaptação, têm-se um novo grupo de indicadores, denominado indicadores industriais de ecoeficiência (Figura 4) que visam abranger as variáveis necessárias para compor um adequado instrumento de mensuração da ecoeficiência em ambiente organizacional.

\begin{tabular}{|c|c|}
\hline INDICADOR & DESCRIÇÃO \\
\hline $\begin{array}{l}\text { Indicador A: Valor } \\
\text { econômico direto gerado }\end{array}$ & $\begin{array}{l}\text { Capacidade de geração de capital pela comercialização de produtos, subprodutos, } \\
\text { economias resultantes da eficiência e eficácia de produtos. }\end{array}$ \\
\hline $\begin{array}{l}\text { Indicador B: Produtos } \\
\text { vendidos }\end{array}$ & $\begin{array}{l}\text { Colocação de produtos no mercado de forma efetiva e competitiva, a fim de maximizar as } \\
\text { vendas. }\end{array}$ \\
\hline Indicador C: Infraestrutura & $\begin{array}{l}\text { Realização em infraestrutura utilizada no desenvolvimento de produtos e serviços, que } \\
\text { resultem em menor impacto ambiental na produção e gestão dos produtos e subprodutos }\end{array}$ \\
\hline $\begin{array}{l}\text { Indicador D: Materiais } \\
\text { usados (matérias- primas) }\end{array}$ & $\begin{array}{l}\text { Escolha e compra das melhores matérias-primas, tanto em qualidade, quantidade, preço e } \\
\text { caráter ambiental (matérias-primas recicladas ou produzidas/extraídas com baixo impacto } \\
\text { ambiental). }\end{array}$ \\
\hline $\begin{array}{l}\text { Indicador E: Consumo de } \\
\text { energia (todas as } \\
\text { modalidades) }\end{array}$ & $\begin{array}{l}\text { Minimização ou neutralização do consumo de energia nas diversas atividades da } \\
\text { organização, ou uso de energias alternativas de baixo impacto ambiental. Considerando } \\
\text { todas as fontes de energia, sejam estas compradas de outras empresas, ou produzidas a } \\
\text { partir de combustíveis, queima de resíduos, entre outras }\end{array}$ \\
\hline $\begin{array}{l}\text { Indicador F: Retirada e } \\
\text { descarte de água }\end{array}$ & $\begin{array}{l}\text { Retirada, uso e descarte de água de forma eficiente e racional, a fim de minimizar o seu } \\
\text { consumo, ou promover a reutilização. }\end{array}$ \\
\hline $\begin{array}{l}\text { Indicador G: Disposição de } \\
\text { subprodutos }\end{array}$ & $\begin{array}{l}\text { Disposição adequada de subprodutos, resíduos, efluentes etc., tratando-os e/ou dispondo- } \\
\text { os de forma adequada a fim de não causar danos ao meio ambiente. }\end{array}$ \\
\hline $\begin{array}{l}\text { Indicador H: Emissões de } \\
\text { gases causadores do efeito } \\
\text { estufa, substâncias } \\
\text { destruidoras da camada de } \\
\text { ozônio, e danosas a } \\
\text { atmosfera } \\
\end{array}$ & $\begin{array}{l}\text { Minimização ou neutralização das emissões de gases causadores do efeito estufa, } \\
\text { substâncias destruidoras da camada de ozônio, e danosas à atmosfera ou à saúde humana }\end{array}$ \\
\hline $\begin{array}{l}\text { Indicador I: Reciclagem de } \\
\text { resíduos }\end{array}$ & $\begin{array}{l}\text { Reciclagem dos resíduos (sólidos, líquidos e gasosos) provenientes das atividades } \\
\text { produtivas. }\end{array}$ \\
\hline $\begin{array}{l}\text { Indicador J: Adequação à } \\
\text { novas demandas de mercado }\end{array}$ & $\begin{array}{l}\text { Capacidade de adequação dos produtos e processos às novas demandas do mercado, tais } \\
\text { como exigência de novos produtos, novas legislações e regulamentações. }\end{array}$ \\
\hline $\begin{array}{l}\text { Indicador K: Efetividade } \\
\text { em Pesquisa e } \\
\text { Desenvolvimento } \\
\end{array}$ & $\begin{array}{l}\text { Capacidade de realização de pesquisas e desenvolvimento de novas tecnologias e } \\
\text { produtos com caráter ambientalmente adequado, reduzindo os impactos ambientais e } \\
\text { resultando em retornos à organização, ainda que não seja uma demanda do mercado. }\end{array}$ \\
\hline
\end{tabular}

Figura 4. Indicadores industriais de ecoeficiência

Fonte: Elaborado com base nos indicadores do GRI (2006) e WBCSD (2000), e nos apontamentos de OECD (1993), Meadows (1998), Maxime, Marcotte e Arcand (2006). 
Algumas explicações relevantes a respeito da elaboração destes indicadores são:

$>$ Foram desconsideradas medidas e quantidades, uma vez que, no contexto deste trabalho, compreende-se ser importante a existência da competência organizacional, que, por sua vez, irá gerar entregas;

$>\mathrm{O}$ grupo de indicadores incorpora a legislação ambiental, sendo considerada premissa básica para a sustentabilidade organizacional e a ecoeficiência, assim, não contempla indicadores presentes na legislação;

$>$ Por fim, buscou-se a clara definição de suas fronteiras, conferindo prioridade às áreas de controle direto da empresa, mas nem por isso negligenciando questões relevantes que fazem parte da cadeia produtiva.

Tendo, a partir de então, um grupo de indicadores para trabalhar a ecoeficiência, resgata-se a discussão sobre competências, e tais indicadores passarão a ser discutidos a partir deste olhar. Conforme já mencionado por Munck, Munck e Souza (2011), a ecoeficiência é vista como uma competência de apoio à sustentabilidade organizacional. Por sua vez, a competência ecoeficiência conta com um grupo de entregas que permitem afirmar a existência de competência em ação. Assim, conhecendo as entregas de uma dada competência torna-se possível avaliar a sua presença ou não na organização.

Para compor a relação de entregas da competência ecoeficiência retomam-se os indicadores industriais de ecoeficiência, que, por serem indicativos básicos para mensuração da ecoeficiência, fornecem apontamentos do que a organização deve entregar. A vantagem de trabalhar com as entregas esperadas é a maior facilidade de visualizá-las e identificá-las na organização, uma vez que se tratam de ações.

A partir deste caminho percorrido até aqui se chegou ao conjunto de indicadores de ecoeficiência apresentados, assim, a seção seguinte apresentará a metodologia adotada, a qual levará para campo o instrumento recém-criado, de medição da ecoeficiência.

\section{MÉTODO DE PESQUISA}

Esta pesquisa teve abordagem mista (qualitativa e quantitativa), desenvolvida em duas fases. $\mathrm{Na}$ primeira fase, a qualitativa, a pesquisa bibliográfica permitiu a criação dos indicadores industriais de ecoeficiência, que subsidiaram a segunda fase da pesquisa. Ainda nesta fase foi conduzido um estudo de caso em uma indústria de acumuladores de energia - baterias automotivas, onde foram realizadas entrevistas semiestruturadas e pesquisa documental. As entrevistas foram realizadas com pessoas que detinham relevante conhecimento dos processos produtivos, sendo dois gestores do Departamento de Recursos Humanos - DRH que participaram de uma mesma entrevista e um gestor do Departamento de Gestão da Qualidade - DGQ. Os documentos analisados foram cartilhas e manuais internos da organização que mostraram detalhes do processo produtivo e das políticas da organização.

$\mathrm{Na}$ fase quantitativa, foi elaborado um questionário, tendo como base os indicadores da figura 4 e apresentado na figura 5, que foi aplicado a 13 gestores e 23 colaboradores de níveis hierárquicos inferiores (denominados a partir de então apenas como colaboradores). Os respondentes foram selecionados aleatoriamente, sendo de diversos setores de acordo com a disponibilidade de participar da pesquisa em seu período de realização. 


\begin{tabular}{|c|c|c|c|c|c|c|c|}
\hline & \multirow[b]{2}{*}{$\begin{array}{r}\text { ENTREGA } \\
\text { ESPERADA }\end{array}$} & \multirow[b]{2}{*}{$\begin{array}{l}\text { DESCRIÇÃO DA } \\
\text { ENTREGA }\end{array}$} & \multicolumn{5}{|c|}{ MENSURAÇÃO DA ENTREGA } \\
\hline & & & \begin{tabular}{|c|} 
A empresa \\
não atende o \\
fator avaliado
\end{tabular} & $\begin{array}{l}\text { O fator encontra- } \\
\text { se em estágio de } \\
\text { desenvolviment } \\
\underline{\underline{0}}\end{array}$ & $\begin{array}{l}\text { A empresa detém } \\
\text { o pleno } \\
\frac{\text { atendimento do }}{\text { fator avaliado }}\end{array}$ & $\begin{array}{c}\text { A empresa } \\
\text { registra a } \\
\text { superação do } \\
\text { fator avaliado }\end{array}$ & $\frac{\text { Não se }}{\text { aplica }}$ \\
\hline $\mathrm{A}$ & \multirow{4}{*}{\multicolumn{2}{|c|}{$\begin{array}{l}\text { Entregas e suas respectivas descrições } \\
\text { de acordo com o Quadro } 13\end{array}$}} & & & & & \\
\hline $\mathrm{B}$ & & & & & & & \\
\hline$\frac{\ldots}{N}$ & & & & & & & \\
\hline $\mathrm{K}$ & & & & & & & \\
\hline
\end{tabular}

Figura 5. Modelo do questionário

Fonte: Elaborado pelo autor

$\mathrm{Na}$ análise de dados, diferentes técnicas foram utilizadas de acordo com a natureza dos dados. As entrevistas foram gravadas, resultando em, aproximadamente, uma hora de gravações, e, posteriormente, transcritas. Juntamente com os documentos foram submetidas à análise de conteúdo e categorização de dados.

Para análise dos questionários foi utilizada a metodologia sugerida por Dutra (2001), em que as alternativas marcadas foram somadas recebendo pesos (zero, um, dois ou três) e então localizadas em uma escala numérica criada a partir da máxima pontuação que cada item pode receber. De posse do instrumento (figura 4), a escala para mensuração da competência ecoeficiência foi construída, primeiramente, atribuindo-se pontos para os diferentes estágios de desenvolvimento das entregas, sendo os pontos crescentes de acordo com o grau de desenvolvimento. Aos itens 'Não atende' e 'Não se aplica' foi atribuído o peso '0'; o item 'Em desenvolvimento' recebeu o peso '1'; 'Atende', o peso '2'; e 'Supera', o peso '3'.

A partir de então, foi calculado o máximo de pontos que cada grau de desenvolvimento ('Em desenvolvimento', 'Atende' e 'Supera') poderia receber. No caso dos gestores, analisando-se a coluna 'Em desenvolvimento', que possui peso 1, considerando a existência de 11 entregas (de A a K) e, supondo que todos os 13 gestores respondentes marcassem esta coluna para todas as entregas, a pontuação máxima obtida seria 143. Caso todos os respondentes marcassem 'Atende' para todas as entregas, e considerando que o peso neste caso é 2, o máximo de pontos seria 286 . Tal cálculo foi realizado com a coluna 'Supera' que permite a pontuação máxima de 429.

A fim de conferir a escala um caráter mais didático, com números menores, permitindo análises mais rápidas, foi realizada uma simplificação. A simplificação feita consistiu em uma divisão de todos os valores por um fator de simplificação comum $(35,8)$, como mostra a Tabela 1 , resultando, então, na escala expressa na Figura 6 . O valor da simplificação $(35,8)$ foi elencado por ser o menor valor que permite resultados inteiros para todos os números da escala.

Tabela 1. Itens constitutivos da escala utilizada para análise do grau de desenvolvimento das entregas, na percepção dos gestores.

\begin{tabular}{lccccc}
\hline & $\begin{array}{c}\text { Não atende Em desenvolvimento } \\
\text { (0 pontos) }\end{array}$ & $\begin{array}{c}\text { Atende } \\
\text { (1 ponto) }\end{array}$ & $\begin{array}{c}\text { Supera } \\
\text { (2 pontos) }\end{array}$ & $\begin{array}{c}\text { Não se aplica } \\
\text { (3 pontos) }\end{array}$ & (0 pontos) \\
\hline Máximo de pontos & 0 & 143 & 286 & 429 & 0 \\
Escala & & 0 a 143 & 144 a 286 & 287 a 429 & \\
Simplificação & & $/ 35,8$ & 135,8 & $/ 35,8$ & \\
Escala utilizada & & 0 a 4 & 5 a 8 & 9 a 12 & \\
\hline
\end{tabular}

Fonte: Elaborado pelo autor

\begin{tabular}{|c|c|c|c|c|c|c|c|c|c|c|c|}
\hline \multicolumn{4}{|c|}{ Em desenvolvimento } & \multicolumn{4}{|c|}{ Atende } & \multicolumn{4}{|c|}{ Supera } \\
\hline 1 & 2 & 3 & 4 & 5 & 6 & 7 & 8 & 9 & 10 & 11 & 12 \\
\hline
\end{tabular}

Figura 6. Escala de avaliação das entregas

Fonte: Elaborado pelo autor

Para construção da escala dos colaboradores, o processo foi análogo ao da escala construída para os gestores. A única modificação foi em relação ao fator de simplificação, pois para que a escala se mantivesse igual a aplicada aos gestores, precisou ser alterado (passando de 35,8 para 
63,3), uma vez que o número de respondentes foi maior, tendo como resultado uma escala igual a aplicada aos gestores (já apresentado na Figura 6).

\section{ANÁLISE E DISCUSSÃO DOS RESULTADOS}

Ao serem tratados assuntos de caráter ambiental, os entrevistados do Departamento de Recursos Humanos - DRH declararam que "Desde a fundação da empresa [a questão ambiental] é um valor que a empresa prega, e sempre foi uma preocupação dos fundadores e da direção preservar o meio ambiente, principalmente por se tratar de uma empresa que lida com metais pesados". O entrevistado do Departamento de Gestão da Qualidade - DGQ também mostra preocupação da organização com o meio ambiente dizendo que "Não podemos usar a nossa atividade [...] para ganhar dinheiro [...] prejudicando o ambiente, nosso e das futuras gerações." Tais informações também estão presentes nos documentos analisados.

Quando questionado sobre a influência das atividades de caráter ambiental na produção e faturamento o entrevistado DGQ diz que "[...] Isso facilita a aquisição de matéria prima, porque se não fizéssemos a logística reversa ${ }^{1}$ [...] nós teríamos mais dificuldades em conseguir matéria prima”. Assim, para a reciclagem do material utilizado, o entrevistado explica que o produto usado "[...]é transformado em matéria prima nova e já entra para o processo. Ao passo que quando você tem que importar, tem que primeiro pagar a vista e aguardar esse material chegar, às vezes 40 ou 45 dias." Desta forma, a organização é $95 \%$ autossuficiente em relação ao seu principal insumo (o chumbo).

Verifica-se que a escassez da matéria-prima conduziu a organização a desenvolver novas formas para obtenção de insumos. Assim, a logística reversa pode ser citada como uma importante competência desenvolvida, o que permite a suposição de que a necessidade é um forte fator no desenvolvimento de novas competências. É possível que a competência estivesse latente na organização, mas somente pode ser considerada quando gerar entregas.

Havendo, assim, indícios de que a organização trabalhe a ecoeficiência, realizou-se a análise dos demais dados coletados por meio de questionário, para mensurar o grau de desenvolvimento da competência ecoeficiência.

Do questionário aplicado emergiram os dados apresentados na Tabela 2, que se referem aos gestores, e na Tabela 3, referente aos colaboradores e, para cada entrega (representadas pelas letras de $\mathrm{A}$ a $\mathrm{K}$ ), as linhas indicam a quantidade de respondentes que assinalaram a alternativa.

Tabela 2. Resultado dos questionários aplicados aos gestores.

\begin{tabular}{lccccc}
\hline Entregas & Não Atende & Em Desenvolvimento & Atende & Supera & Não Se Aplica \\
\hline A & $5(38,5 \%)$ & $8(61,5 \%)$ & & \\
B & $8(61,5 \%)$ & $5(38,5 \%)$ & & \\
C & $6(46,2 \%)$ & $6(46,2 \%)$ & $1(7,7 \%)$ & \\
D & $5(38,5 \%)$ & $4(30,8 \%)$ & $4(30,8 \%)$ & \\
E & $1(7,7 \%)$ & $11(84,6 \%)$ & $1(7,7 \%)$ & & \\
F & & $5(38,5 \%)$ & $3(23,1 \%)$ & $5(38,5 \%)$ & \\
G & $2(15,4 \%)$ & $4(30,8 \%)$ & $7(53,8 \%)$ & \\
H & $5(38,5 \%)$ & $7(53,8 \%)$ & & $1(7,69 \%)$ \\
J & & & $11(84,6 \%)$ & $2(15,4 \%)$ & \\
L & & $6(46,2 \%)$ & $7(53,8 \%)$ & $1(7,7 \%)$ & \\
M & & $7(53,8 \%)$ & $3(23,1 \%)$ & $3(23,1 \%)$ & \\
\hline Totais & $1(0,7 \%)$ & $60(41,7 \%)$ & $59(41,0 \%)$ & $23(16,0 \%)$ & $1(0,7 \%)$ \\
\hline
\end{tabular}

Fonte: Elaborado pelo autor

1 Trata-se da recuperação de, ao menos, uma parcela de produtos após seu ciclo de vida útil, os quais retornam ao ciclo produtivo de alguma maneira. Na Enermais, na venda do produto, parte do pagamento é feito com material usado, que é destinado para a reciclagem. 
Tabela 3. Resultado dos questionários aplicados aos colaboradores

\begin{tabular}{|c|c|c|c|c|c|}
\hline Entregas & Não atende & Em Desenvolvimento & Atende & Supera & Não se aplica \\
\hline $\mathbf{A}$ & & $3(13,0 \%)$ & $20(87,0 \%)$ & & \\
\hline B & & $7(30,4 \%)$ & $16(69,9 \%)$ & & \\
\hline $\mathbf{C}$ & & $7(30,4 \%)$ & $14(60,9 \%)$ & $2(8,7 \%)$ & \\
\hline D & & $5(21,7 \%)$ & $15(65,2 \%)$ & $3(13,0 \%)$ & \\
\hline $\mathbf{E}$ & $2(8,7 \%)$ & $10(43,5 \%)$ & $9(39,1 \%)$ & & $2(8,7 \%)$ \\
\hline $\mathbf{F}$ & $1(4,3 \%)$ & $4(17,4 \%)$ & $11(47,8 \%)$ & $6(26,1 \%)$ & $1(4,3 \%)$ \\
\hline G & & & $12(52,2 \%)$ & $11(47,8 \%)$ & \\
\hline $\mathbf{H}$ & & $3(13,0 \%)$ & $14(60,9 \%)$ & $3(13,0 \%)$ & $3(13,0 \%)$ \\
\hline $\mathbf{I}$ & & $1(4,3 \%)$ & $14(60,9 \%)$ & $8(34,8 \%)$ & \\
\hline $\mathbf{J}$ & & $7(30,4 \%)$ & $11(47,8 \%)$ & $5(21,7 \%)$ & \\
\hline $\mathbf{K}$ & & $3(13,0 \%)$ & $13(56,5 \%)$ & $7(30,4 \%)$ & \\
\hline Totais & $3(1,2 \%)$ & $50(19,8 \%)$ & $149(58,9 \%)$ & $45(17,8)$ & $6(2,4 \%)$ \\
\hline
\end{tabular}

Fonte: Elaborado pelo autor

Atribuindo os respectivos pesos para a quantidade de respostas em cada coluna e localizando os dados na escala, como previamente explicado na metodologia, têm-se que, na percepção dos gestores, a organização obteve a pontuação 6,9 , enquanto a percepção dos colaboradores gerou a nota 7,6, conforme mostra a Figura 7.

\begin{tabular}{|c|c|c|c|c|c|c|c|c|c|c|c|c|}
\hline & \multicolumn{4}{|c|}{ Em desenvolvimento } & \multicolumn{4}{|c|}{ Atende } & \multicolumn{4}{|c|}{ Supera } \\
\hline & 1 & 2 & 3 & 4 & 5 & 6 & 7 & 8 & 9 & 10 & 11 & 12 \\
\hline $\begin{aligned} \text { Gestores } & \rightarrow \\
\text { Colaboradores } & \rightarrow \\
\text { Média } & \rightarrow\end{aligned}$ & & & & & & & $X$ & $\begin{array}{l}X \\
X\end{array}$ & & & & \\
\hline
\end{tabular}

Figura 7. Escala de mensuração do nível de entregas da competência ecoeficiência

Fonte: Elaborado pelo autor

De acordo com a percepção dos respondentes, a empresa pesquisada apresenta um bom nível de desenvolvimento da ecoeficiência uma vez que atende a competência e aproxima-se, ainda, do estágio de superação. Tal resultado ganha força com as entrevistas realizadas que mostram o alinhamento da organização com as sustentabilidades econômica e ambiental. A partir de então, pode-se constatar indícios de que as políticas e os valores organizacionais influem no desenvolvimento da competência ecoeficiência. Tais políticas e valores podem ser traduzidos como um agir, dotado de intencionalidade e racionalidade, já que está pautado nas decisões da organização e que pode ser compreendida como um agente estruturante. Tal observação infere que o desenvolvimento de competências pode ser resultado de processos inconscientes, mas não se afastam de processos intencionais e limitados assim como a razão humana, pois, para Maggi (2006), as características humanas são passadas para a organização.

Pelo resultado dos questionários, constatou-se que há indícios do alinhamento entre os diferentes níveis organizacionais, concordando com Mills et al. (2002) quando estes postam que a competência é uma habilidade e característica global presente em toda organização. No exemplo do Octeto em fá maior D803, embora cada músico desejasse tocar a obra não podia fazê-lo sozinho, pois a execução da música exige a cooperação de todos. Contrapondo tal exemplo à organização pesquisada, visualiza-se o desenvolvimento da competência ecoeficiência de forma cooperada.

A característica de auto-organização do agir ocorre por meio da criação de ordem e de regras, as quais são variáveis, formais e informais, explícitas e tácitas, conscientes e não conscientes, prévias e intrínsecas à ação. Os entrevistados DRH comentam que os colaboradores têm muitas atitudes desenvolvidas em razão do ambiente, embora não sejam regras da organização. Os entrevistados citam a preocupação de colaboradores em destinar resíduos em locais correspondentes embora não existam regras da organização para tal. Regras informais como estas 
são construídas e institucionalizadas no decorrer do desenvolvimento do processo. Assim, torna-se claro que, embora não apresente rigidez, é um agir com caráter regulatório dos processos, denominado então de agir estruturante. Para Maggi (2006), o agir pode mostrar como a organização busca atingir seus objetivos, ou seja, os meios utilizados para tal (entregas), tornando o agir dotado de sentido.

Conforme discutido, deter os elementos da competência não é sinônimo de entrega, por isso o instrumento utilizado visou trabalhar com as entregas, que, por sua vez, permitem avaliar a competência em ação. Deste modo, pode-se inferir, com maior propriedade, que a organização pesquisada detém a competência ecoeficiência e, a partir desta, vem gerando entregas. $\mathrm{O}$ desenvolvimento de tal competência confirma o exposto pelas entrevistas e pelos documentos, $\mathrm{o}$ que indica ser um trabalho constantemente alimentado e realimentado que busca trabalhar as competências individuais.

O desenvolvimento da competência ecoeficiência pode ser traduzido em agires, uma vez que trata de uma forma de ver a organização como processos, que, por sua vez, são duradouros, nunca terminados e, ainda, dotados de racionalidade (agir intencional e limitado); ou seja, tal agir nunca é acabado por ser um trabalho de longo prazo que precisa estar sempre sendo realimentado. É ainda intencional e limitado, pois é gerenciado e, por tanto, absorve a racionalidade dos gestores.

Embora os gestores e colaboradores tenham sido separados no momento da aplicação do questionário, ambos desempenham seus papéis igualmente importantes para o desenvolvimento da competência. Desta forma, destaca-se, pela pesquisa, o alinhamento dos agires dos gestores e dos colaboradores, uma vez que estes têm suas percepções da organização e dos processos de forma semelhante. Ou, também, pode-se dizer que ambos vêm executando a obra conjuntamente, demonstrando assim a presença das características do agir: finalização, estruturação do processo e cooperação.

Tendo, portanto, sido apresentados os dados obtidos a partir da pesquisa empírica e discutido com aporte no referencial teórico, passar-se-á, no capítulo seguinte para as considerações finais do trabalho.

\section{CONSIDERAÇÕES FINAIS}

O referencial teórico apresentou o debate em torno da sustentabilidade organizacional e o TBL, que destacou a framework de sustentabilidade organizacional apresentada por Dias et al. (2011) e também trabalhada por Munck, Munck e Souza (2011) ao inserir o agir organizacional com a lógica das competências. Com o intuito de mensurar os elementos da sustentabilidade organizacional, diante de sua amplitude, selecionou-se, por meio deste trabalho, a ecoeficiência como foco. Indicadores para tal foram criados e convertidos em um instrumento de mensuração do desenvolvimento da competência ecoeficiência.

A pesquisa empírica, além de buscar suporte em entrevistas e documentos, aplicou o instrumento de mensuração da competência ecoeficiência, mostrando que tal competência pode ser operacionalizada e mensurada, além de apresentar um panorama do grau de desenvolvimento na organização pesquisada. Os indicadores utilizados como critérios para a avaliação podem ser considerados representativos do fenômeno.

Sendo possível compreender a ecoeficiência como uma competência organizacional, inferese que o conjunto de indicadores criados é uma alternativa inovadora e viável para aplicação na organização. Diz-se inovadora ao introduzir a lógica das competências como articuladora do processo; viável por ser acessível às organizações, seus gestores e demais colaboradores e; ainda, capaz de evidenciar o atual estágio de desenvolvimento da competência ecoeficiência. Assim, tal modelo mostra-se como um importante avanço, tanto na obtenção de um instrumento para mensuração da ecoeficiência quanto para as organizações identificarem o desenvolvimento de sua competência. Desta forma, a importância de um instrumento de mensuração consistente se revelará a partir do momento em que outras organizações passarem a utilizá-lo. Nesse cenário, será possível

Revista de Gestão Social e Ambiental - RGSA, São Paulo, v. 8, n. 1, p. 73-88, jan./abr., 2014. 
estabelecer parâmetros comparativos, o que virá a enriquecer ainda mais os resultados obtidos.

No decorrer da pesquisa empírica, evidenciou-se que as políticas disseminadas pela organização pesquisada não tratam uma ou outra sustentabilidade com prioridade, tratando a SO econômica e ambiental de forma equivalente. A exigência do alinhamento de todos os seus colaboradores com o que é pronunciado pela organização também reflete o desenvolvimento da competência ecoeficiência. Contudo, outro fator que merece destaque é a escassez de matériasprimas, abordado pelo entrevistado DGQ, que demandou da organização o desenvolvimento de outras competências que, por sua vez, se configuraram como apoio para a ecoeficiência. Desta forma, é possível inferir que, as condições do meio e as necessidades atuam como fortes demandas de agires para o negócio, o que, por sua vez, resulta no desenvolvimento de competências, que, neste caso, resultou no desenvolvimento ecoeficiência.

No que diz respeito ao objetivo inicial desse artigo, tem-se como um resultado do trabalho um instrumento de mensuração da ecoeficiência com base nas competências, que permite identificar o grau de desenvolvimento do fenômeno. A concepção deste instrumento baseado na lógica das competências mostra-se como um instrumento ainda não explorado que confere maior relevância aos indicadores, devido ao seu pragmatismo advindo ao trabalhar com entregas. Em relação à organização pesquisada, o resultado apontou que a empresa é detentora de bom nível de desenvolvimento da competência ecoeficiência.

Para futuras pesquisas, sugere-se a aplicação do instrumento em outras organizações, permitindo, criação de parâmetros para comparações. Sugere-se também que sejam investigadas as competências de apoio justiça socioambiental e inserção socioeconômica, a fỉm de compor um quadro completo de análise da sustentabilidade organizacional.

\section{REFERÊNCIAS}

Callado, A. L. C. (2010) Modelo de mensuração de sustentabilidade empresarial: uma Aplicação em Vinícolas localizadas na Serra Gaúcha. Tese de doutorado, Universidade Federal do Rio Grande do Sul, Porto Alegre, Rs, Brasil.

Dias, B. G., Munck, L., Bansi, A. C., Cella-De-Oliveira, F. A. (2011) Bases compreensivas da sustentabilidade organizacional: a proposição de uma estrutura conceitual (Framework). Seminário em Administração, São Paulo, SP, Brasil, 16.

Dillick, T., Hockerts, K. (2002) Beyound the business case for corporate sustentability. Business Strategy and the environment, 11, 130-141.

Dutra, J. S. (2001) Gestão do desenvolvimento e da carreira por competência. In: Dutra, J. S. (org.) Gestão por competências: um modelo avançado para o gerenciamento de pessoas. (8 ed.) São Paulo: Gente.

Elkington, J. (1999) Cannibals with forks: the triple bottom line of 21st century business. Oxford: Capstone Publishing Limited.

Global Reporting Initiative - GRI. (2006) Diretrizes para relatórios de sustentabilidade. Boston: GRI.

Hamel, G., Prahalad, C.K. (1990) The core competence of the corporation. Harvard Business Review, 68(3), 79-91.

- (1995) Competindo pelo futuro: estratégias inovadoras para obter o controle do seu setor e criar os mercados de amanhã. (10 ed.) Rio de Janeiro: Campus. 
(1994) The concept of core competence. In: Hamel, G., Heene, A. Competence-based competition. West Sussex, England: John Wiley \& Sons Ltda.

Hanai, F. Y. (2009) Sistema de Indicadores de Sustentabilidade: uma aplicação ao contexto de desenvolvimento do turismo na região de Bueno Brandão, estado de Minas Gerais, Brasil. Tese de doutorado, Universidade de São Paulo (USP), São Carlos, SP, Brasil.

Jamali, D. (2006) Insights into the triple bottom line integration from a learning organization perspective. Business Process Management Journal, 12(6), 809-821.

Kranjc, D., Glavic, P. A. (2005) model for integrated assessment of sustainable development. Resources, Conservation and Recycling, 43(2).

Lemme, C. F. (2010) O valor gerado pela sustentabilidade corporativa. In: Lins, L., Zylbersztajn, D. Sustentabilidade e geração de valor: a transição para o século XXI. Rio de Janeiro: Elsevier.

Lins, L., Zylbersztajn, D. (2010) Sustentabilidade e geração de valor: a transição para o século $X X I$. Rio de Janeiro: Elsevier.

Maggi, B. (2006) Do agir organizacional: um ponto de vista sobre o trabalho, o bem-estar, a aprendizagem. São Paulo: Edgard Blucher.

Maxime, M., Marcotte, M., Arcand, Y. (2006) Development of eco-efficiency indicators for the Canadian food and beverage industry. Journal of Cleaner Production, 14, 636-648.

Meadows, D. (1998) Indicators and information systems for sustainable development: a report to the Balaton Group. Hartland: The Sustainability Institute.

Mills, J., Platts, K., Bourne, M., Richards, H. (2002) Strategy and performance: competing through competences. Cambridge: Cambridge University Press.

Munck, L., Munck, M. M. G., Souza, R. B. (2011) Sustentabilidade organizacional: a proposição de uma framework representativa do agir competente para seu acontecimento. Gerais: Revista Interinstitucional de Psicologia, 4(2), 147-158.

Organization For Economic Co-Operation And Development - OECD. (1993) Core set of indicators for environmental performance reviews: a synthesis report by the Group on the State of the Environment. Environment monographs, 83.

Petinelli-Souza, S., Machado, L. A. D. (2006) Pensando as competências para além da perspectiva funcionalista. Revista de gestão da USP, 13(3), 1-11.

Salgado, V. G. (2007) Indicadores de ecoeficiência e o transporte de gás natural. Rio de Janeiro: Interciência.

Savitz, A. W., Weber, K. (2006) The triple bottom line: how today's best-run companies are achieving. San Francisco: John Wiley \& Sons Inc. 
Schaffel, S. B. (2010) Em busca da eco-sócio eficiência no caso da agricultura familiar voltada para a produção de biodiesel no Brasil. Tese de doutorado, Universidade Federal do Rio de Janeiro (UFRJ), Rio de Janeiro, RJ, Brasil.

Schmidheiny, S., Wbcsd - World Business Council For Sustainable Development. (1992) Changing course: a global business perspective on development and the environment. Cambridge: MIT Press.

Schaltegger, T., Wagner, M. (2005) Current trends in environmental cost accounting - and its interaction with eco-efficiency performance measurement and indicators. Eco-Efficiency in Industry and Science, 18, 45-62.

Souza, R. B. (2010) O alinhamento entre sustentabilidade e competências em contexto organizacional. Dissertação de Mestrado, Universidade Estadual de Maringá (UEM) / Universidade Estadual de Londrina (UEL), Londrina, PR, Brasil, 2010.

Turner, D., Crawford, M. (1994) Managing current and future competitive performance: the role of competence. In: Hamel, G., Heene, A. Competence-based competition. England: John Wiley \& Sons.

Vos, R. O. (2007) Defining sustainability: a conceptual orientation. Journal of Chemical Technology and Biotechnology, 82(4), 334-339.

World Business Council For Sustainable Development - WBCSD (2000) Ecoefficiency: Creating More Value With Less impact. Geneva, Switzerland: WBCSD.

. Measuring Ecoefficiency: (2000a) A guide to Reporting Company Performance. Geneva, Switzerland: WBCSD.

Young, W., Tilley, F. (2006) Can businesses move beyond efficiency? The shift toward effectiveness and equity in the corporate sustainability debate. Business Strategy and the Environment, 15, 402-415.

Data da submissão: 30/10/2013

Data da publicação: 30/04/2014 